\title{
Cognitive impairments in patients with persistent symptoms attributed to Lyme disease
}

Anneleen Berende ${ }^{1 *}$ D, Joost Agelink van Rentergem², Andrea W. M. Evers ${ }^{3,4}$, Hadewych J. M. ter Hofstede ${ }^{1}$, Fidel J. Vos ${ }^{1,5}$, Bart Jan Kullberg ${ }^{1}$ and Roy P. C. Kessels ${ }^{3,6}$

\begin{abstract}
Background: Persistent symptoms attributed to Lyme borreliosis often include self-reported cognitive impairment. However, it remains unclear whether these symptoms can be substantiated by objective cognitive testing.

Methods: For this observational study, cognitive performance was assessed in 280 adults with persistent symptoms attributed to Lyme borreliosis (as part of baseline data collected for the Dutch PLEASE study). Cognitive testing covered the five major domains: episodic memory, working memory / attention, verbal fluency, informationprocessing speed and executive function. Patients' profiles of test scores were compared to a large age-, educationand sex-adjusted normative sample using multivariate normative comparison. Performance validity was assessed to detect suboptimal effort, and questionnaires were administered to measure self-reported cognitive complaints, fatigue, anxiety, depressive symptoms and several other psychological factors.

Results: Of 280 patients, one was excluded as the test battery could not be completed. Of the remaining 279 patients, 239 (85.4\%) displayed sufficient performance validity. Patients with insufficient performance validity felt significantly more helpless and physically fatigued, and less orientated. Furthermore, they had a lower education level and less often paid work. Of the total study cohort 5.7\% $(n=16)$ performed in the impaired range. Among the 239 patients who displayed sufficient performance validity, 2.9\% $(n=7)$ were classified as cognitively impaired. No association between subjective cognitive symptoms and objective impairment was found.
\end{abstract}

Conclusions: Only a small percentage of patients with borreliosis-attributed persistent symptoms have objective cognitive impairment. Performance validity should be taken into account in neuropsychological examinations of these patients. Self-report questionnaires are insufficiently valid to diagnose cognitive impairment.

Trial registration: ClinicalTrials.gov NCT01207739. Registered 23 September 2010.

Keywords: Lyme disease, Cognitive neuropsychology, Cognition, Borrelia

\section{Background}

Patients with persistent symptoms attributed to Lyme borreliosis often report a variety of cognitive symptoms. However, subjective cognitive symptoms are not always due to underlying cognitive impairments. Previously, subjective ratings of memory capabilities and objective memory performance were only weakly correlated in

\footnotetext{
* Correspondence: Anneleen.Berende@radboudumc.nl

'Department of Internal Medicine 463 and Radboud Center for Infectious

Diseases, Radboud University Medical Center, P.O. Box 9101, 6500, HB,

Nijmegen, the Netherlands

Full list of author information is available at the end of the article
}

patients with post-treatment Lyme disease [1]. Most previous studies that compared cognitive performance of Lyme patients to performance of healthy controls found a worse performance in Lyme patients at group level [212]. The most affected cognitive domain was episodic memory. Findings concerning the domains verbal fluency and processing speed were less consistent. However, most studies were relatively small $(n<80)$, originated from the US, and used diverse inclusion criteria and methods. In the 4 larger US studies, mild to no cognitive abnormalities were identified $[1,2,12,13]$. As both the Borrelia species and the clinical presentation of

(c) The Author(s). 2019 Open Access This article is distributed under the terms of the Creative Commons Attribution 4.0 International License (http://creativecommons.org/licenses/by/4.0/), which permits unrestricted use, distribution, and 
Lyme disease in Europe and the US differ [14], cognitive function in European Lyme patients requires separate assessment. Furthermore, most previous studies have not taken performance validity into account. This is crucial, as a suboptimal performance results in poor tests scores not reflecting an individual's actual cognitive status. Very recently, the study by Touradji et al. in a group of US patients with post-treatment Lyme disease showed that $24 \%$ of the sample displayed suboptimal effort on measures of performance validity [12]. Hence, suboptimal performance affects the validity and reliability of neuropsychological outcomes, resulting in false positive results (i.e., patients incorrectly labelled as having a cognitive impairment) [15]. This stresses the need to take performance validity testing into account when cognitively assessing patients with persistent symptoms attributed to Lyme disease.

The aim of the present study was to objectively assess cognitive performance using sensitive tests in a large cohort of patients with persistent symptoms attributed to Lyme borreliosis, while taking performance validity into account, and to compare cognitive performance outcomes with subjective symptoms.

\section{Methods}

The current study uses baseline data collected between 2010 and 2013 as part of the Persistent Lyme Empiric Antibiotic Study Europe (PLEASE). Previously, we reported the primary and secondary outcome measures of this multicenter, placebo-controlled, double-blind randomized controlled trial from the Netherlands (ClinicalTrials.gov NCT01207739) [16, 17]. The local Institutional Review Board approved the PLEASE protocol, and informed consent was obtained from each participant. Here we provide a detailed report of the baseline cognitive and self-report questionnaire data. The study population comprises adult patients $(n=280)$ referred with persistent symptoms attributed to Lyme borreliosis, preceded by confirmed symptomatic Lyme disease or accompanied by positive B. burgdorferi IgG or IgM antibodies, as confirmed by means of immunoblot assay. Patients were not required to have received antibiotic treatment before study entry. Major symptoms included musculoskeletal pain, cognitive disturbances and/or fatigue. Details about inclusion and exclusion criteria have been published previously [16].

\section{Outcomes}

Cognitive performance was assessed using an extensive neuropsychological test battery covering five major cognitive domains: episodic memory, working memory / attention, verbal fluency, information-processing speed and executive function. Episodic memory was assessed using the Rey Auditory Verbal Learning Test (RAVLT), working memory / attention with the Digit Span, verbal fluency with the Category Fluency Test (animal/profession naming), and information-processing speed with the Trail Making Test Part A and the mean response time of cards I and II from the Stroop Color-Word Test, and the Symbol-Digit Substitution Test. Executive function was measured using the Interference Score of the Trail Making Test (Part B/Part A) and the Stroop Interference Score (card III/mean of cards I and II). Assessment details have been published previously [17].

To identify participants with insufficient performance validity, the Amsterdam Short Term Memory test (ASTM) was administered [18]. A poor performance on this task indicates suboptimal mental effort. The recommended cut-off score is 85 (maximum score $=90$ ), with $86 \%$ sensitivity and $87 \%$ specificity [19]. However, since our goal was to prioritize optimal specificity (>90\%), adopting a conservative approach that reduces the risk of false alarms on performance validity tests (i.e., incorrectly labelling a participant as someone displaying suboptimal effort), we used a cut-off score of $<83$ (which has a specificity of $95 \%$ and a sensitivity of $76 \%$ ).

Subjective measurement of cognitive function was assessed with the Cognitive Failures Questionnaire (CFQ) [20], fatigue by the Checklist Individual Strength (CIS) [16], anxiety and depressive symptoms by the Hospital Anxiety and Depression Scale (HADS) [21], self-efficacy by a modified version of the Arthritis Self-Efficacy Scale (i.e., 'pain' replaced by 'physical symptoms') [22], illness cognitions by the Illness Cognition Questionnaire (ICQ) [23], worrying by the Penn-State Worry Questionnaire (PSWQ) [24], neuroticism and extraversion by the Eysenck Personality Questionnaire (EPQ) [25], and fear of body sensations by the Body Sensations Questionnaire (BSQ) [26].

\section{Statistical analysis}

First, we investigated which demographic/psychological factors were associated with poor performance validity. For patients with sufficient performance validity, we determined whether their cognitive performance was impaired by comparing individual test performances to an extensive normative sample $(n=26,939)$ from the Advanced Neuropsychological Diagnostics Infrastructure (ANDI) [27]. We performed a multivariate normative comparison (MNC) on each patient's neuropsychological test profile, applying corrections for age, sex and education level. The MNC provides an individual classification based on the profile of tests as either 'cognitively impaired' or 'cognitively unimpaired' [27].

We explored performance on individual cognitive domains, averaging age-, sex- and education-adjusted zscores per domain. A domain was classified as 'impaired' if $\mathrm{z}<-1.5$ (i.e., more than 1.5 SD below the normative 
mean). The relation between objective cognitive functioning and subjective complaints was analyzed with Pearson correlation coefficients.

Alpha was set at 0.05 throughout (two-tailed), and 95\% confidence intervals are reported when appropriate. Benjamini-Hochberg correction was used to reduce the false discovery rate for multiple comparisons, accepting a false discovery rate of 0.10 .

\section{Results}

Of the 280 patients included, one was unable to perform several neuropsychological tests due to visual impairment unrelated to Lyme disease. Of the 279 patients fully examined, 239 (85.4\%) displayed sufficient performance validity.

Table 1 shows patient characteristics stratified by performance validity status.

Patients with insufficient performance validity had significantly lower education levels and less often paid work. They also reported significantly more feelings of helplessness (ICQ subscale helplessness, $F(1,275)=9.77$ ), experienced more physical fatigue (CIS Activity subscale, $F(1,276)=6.79)$, and reported more problems in daily orientation (CFQ Orientation subscale, $F(1,276)=8.40$ ).

Compared to the normative sample, $2.9 \%$ of patients (7/239) were cognitively impaired. For the separate domains, $2.1 \%$ were impaired on episodic memory $(5 / 239)$, $5.4 \%$ on working memory / attention (13/239), $0.8 \%$ on verbal fluency $(2 / 239), 2.1 \%$ on information-processing speed $(5 / 239)$, and $0.4 \%$ on executive function $(1 / 239)$. Table 2 shows the raw neuropsychological test scores as well as mean $\mathrm{z}$-scores, and percentage of individuals with a cognitive decrement ( $\mathrm{z}$-score $<1.0 \mathrm{SD}$ below the age, sex and education-adjusted normative mean).

No significant correlation between overall cognitive performance and subjective cognitive complaints (CFQ total score) was found in patients with sufficient performance validity $(r=0.120, p=0.064)$. A significant correlation was found between objective performance and problems in orientation (CFQ subscale orientation; $r=0.246(p<0.001)$. Performance and other CFQ subscales did not show any correlations $(p=0.10-0.98)$.

\section{Discussion}

We have assessed neurocognitive function in the largest sample of patients with persistent symptoms attributed to Lyme disease so far, using sensitive tests and extensive normative data. Furthermore, this study was the first European study to take performance validity into account. In our study, $15 \%$ of patients displayed insufficient performance validity using a conservative cut-off that prioritizes specificity over sensitivity (i.e., reducing the chance of incorrectly labelling an individuals as displaying poor performance validity), indicating that their neuropsychological test scores cannot be interpreted reliably as they might not reflect the patients' actual cognitive abilities. Of note, there remains a possibility that this group with insufficient performance validity contains legitimate poor performers. For example, they may have been too fatigued to perform sufficiently. Our percentage of insufficient performance is considerably lower than in the study of Touradji et al. [12] who found that $24 \%$ of their sample of post-treatment Lyme disease patients showed suboptimal effort, which may have been due to our conservative approach in assessing suboptimal effort. These substantial proportions of patients displaying suboptimal effort, however, illustrate the need for performance validity testing when assessing cognition in patients with persistent neuropsychological symptoms [15]. Patients who displayed insufficient effort reported more fatigue, memory-orientation difficulties, and more feelings of helplessness than the optimal performers. Additionally, these patients were more often without paid work and had lower education levels. It should also be noted that only $22.5 \%(9 / 40)$ of the individuals who displayed suboptimal effort would have been classified as 'cognitively impaired' based on the performance on all other neuropsychological tests. After exclusion of patients with poor performance validity, only $2.9 \%$ had impaired cognitive function. This rate is low compared to the high level of cognitive complaints reported by patients (on average about $1 \mathrm{SD}$ above the normative mean on the CFQ) [20]. The lack of correlation between objective and subjective cognitive functioning, was also reported in another large study in patients with Lyme-associated symptoms [1]. This lack of correlation between objective cognitive performance and subjective cognitive complaints is not specific for Lyme, but has been demonstrated in other disorders as well (including HIV, dementia, and rheumatoid arthritis) [28-30]. Subjective cognitive complaints are often associated with depressive symptoms [29]. The percentage of $2.9 \%$ cognitively impaired patients is comparable to what is found in the normal population (i.e., by definition $2.3 \%$ of a normative sample performs worse than $2 \mathrm{SD}$ below the normative mean). Similar to our results, the study by Kaplan et al. [1] found only a small percentage of cognitively impaired individuals. That study also examined personality characteristics, albeit with a smaller sample size and a less extensive test battery than the present study. Another large study did not find any differences between patients and healthy controls in cognitive function either [2]. However, a very recent large study, which did take performance validity into account, found a much higher percentage [12]. Furthermore, two studies by Keilp et al. found distinctive cognitive difference between patients with symptoms attributed to Lyme disease and healthy controls [6, 7]. We can only 
Table 1 Demographic and psychosocial factors stratified by performance validity ${ }^{a}$

\begin{tabular}{|c|c|c|c|}
\hline Characteristic & $\begin{array}{l}\text { Good performance } \\
\text { validity }(n=239)\end{array}$ & $\begin{array}{l}\text { Poor performance } \\
\text { validity }(n=40)\end{array}$ & $P$ Value \\
\hline Women, no. (\%) & $109(45.6)$ & $19(47.5)$ & 0.82 \\
\hline \multicolumn{4}{|l|}{ Education level, no. (\%) } \\
\hline Low ( $\leq 8$ years) & $1(0.4)$ & $0(0)$ & \multirow[t]{3}{*}{0.03} \\
\hline Average (9-11 years) & $125(52.7)$ & $28(71.8)$ & \\
\hline High ( $\geq 12$ years) & $111(46.8)$ & $11(28.2)$ & \\
\hline Paid work, no. (\%) & $154(64.7)$ & $17(43.6)$ & 0.01 \\
\hline Age, mean $( \pm S D)$, years & $48.7(11.9)$ & $49.0(11.9)$ & 0.87 \\
\hline Duration of symptoms, median (IQR), years & $2.7(1.3-6.3)$ & $1.8(0.7-5.7)$ & 0.13 \\
\hline Previous antibiotic treatment for Lyme disease, no. (\%) & $213(89,1)$ & $33(82.5)$ & 0.23 \\
\hline Delay symptom onset and treatment, median (IQR), weeks & $22.5(3.0-103.5)$ & $15.5(2.0-69.0)$ & 0.41 \\
\hline History of meningoradiculitis (neuroborreliosis), no. $(\%)^{c}$ & $18(7.5)$ & $3(7.7)$ & 0.97 \\
\hline \multicolumn{4}{|l|}{ CFQ, mean $(95 \% \mathrm{Cl})$} \\
\hline Orientation & $3.92(3.65-4.18)$ & $4.98(4.20-5.75)$ & $0.004^{b}$ \\
\hline Distractibility & $11.29(10.71-11.87)$ & $12.98(11.58-14.37)$ & 0.03 \\
\hline Blunders & $7.04(6.70-7.38)$ & $7.95(7.15-8.75)$ & 0.05 \\
\hline Memory & $7.32(7.05-7.59)$ & $7.03(6.28-7.77)$ & 0.43 \\
\hline Total & $43.23(41.52-44.94)$ & $47.73(43.24-52.21)$ & 0.05 \\
\hline \multicolumn{4}{|l|}{ HADS, mean $(95 \% \mathrm{Cl})$} \\
\hline Anxiety & $6.36(5.82-6.90)$ & $6.08(4.90-7.26)$ & 0.71 \\
\hline Depression & $7.47(6.98-7.96)$ & $8.76(7.33-10.19)$ & 0.06 \\
\hline \multicolumn{4}{|l|}{ CIS, mean (95\% Cl) } \\
\hline Fatigue severity & $43.62(42.33-44.91)$ & $47.25(44.38-50.11)$ & 0.03 \\
\hline Concentration & $23.84(22.92-24.76)$ & 25.35 (22.74-27.96) & 0.23 \\
\hline Motivation & $16.67(15.92-17.42)$ & 17.93 (15.93-19.92) & 0.22 \\
\hline Activity & $13.92(13.27-14.57)$ & $16.15(14.73-17.57)$ & $0.01^{\mathrm{b}}$ \\
\hline Total & 98.03 (95.34-100.72) & $106.65(100.82-112.49)$ & 0.02 \\
\hline Self-efficacy, mean (95\% Cl) & 17.28 (16.60-17.96) & $15.62(13.92-17.31)$ & 0.07 \\
\hline \multicolumn{4}{|l|}{ ICQ, mean $(95 \% \mathrm{Cl})$} \\
\hline Helplessness & $13.26(12.71-13.80)$ & $15.54(14.20-16.87)$ & $0.002^{b}$ \\
\hline Acceptance & 13.68 (13.17-14.20) & $13.42(12.27-14.58)$ & 0.70 \\
\hline Perceived benefits & 11.35 (10.82-11.88) & $12.63(11.43-13.82)$ & 0.07 \\
\hline \multicolumn{4}{|l|}{ EPQ, mean $(95 \% \mathrm{Cl})$} \\
\hline Neuroticism & $8.27(7.59-8.96)$ & $7.67(6.22-9.12)$ & 0.50 \\
\hline Extraversion & $11.44(10.83-12.04)$ & $12.21(10.60-13.81)$ & 0.34 \\
\hline PSWQ, mean (95\% Cl) & $42.17(40.55-43.78)$ & $42.15(38.30-46.00)$ & 0.99 \\
\hline BSQ, mean $(95 \% \mathrm{Cl})$ & $2.27(2.19-2.35)$ & $2.38(2.17-2.59)$ & 0.33 \\
\hline
\end{tabular}

Abbreviations: $B S Q$ body sensations questionnaire, CFQ Dutch version of the Cognitive Failures Questionnaire, CIS checklist individual strength, EPQ Eysenck Personality Questionnaire, HADS hospital anxiety and depression scale, ICQ illness cognition questionnaire, PSWQ Penn-State Worry Questionnaire a Between-group differences in characteristics were analyzed with analysis of variance for continuous variables, chi-square tests for proportions, and Kruskal-Wallis tests for ordinal variables and data that were not normally distributed

${ }^{b}$ Significant with the Benjamini-Hochberg correction, accepting a false discovery rate of 0.10

${ }^{\mathrm{c}}$ Diagnosis by intrathecal Borrelia antibody production

speculate on an explanation for the difference in impairment for the patients with sufficient performance. Possibly, differences between Borrelia species in the US and Europe may play a role. In addition, differences in recruitment bias across the various studies may also have played a role. For instance, in the paper by Touradji et al. [12] it is stated that participants partially were selfreferred, whereas our patients were all referred to the 
Table 2 Neuropsychological test scores per domain and per test ${ }^{a}$

\begin{tabular}{|c|c|c|c|c|c|c|}
\hline & \multicolumn{3}{|c|}{ Good performance validity $(n=239)$} & \multicolumn{3}{|c|}{ Poor performance validity $(n=40)$} \\
\hline & $\begin{array}{l}\text { mean raw } \\
\text { score (SD) }\end{array}$ & $\begin{array}{l}\text { mean } \\
\text { z-score (SD) }\end{array}$ & $\begin{array}{l}\text { cognitive decrement } \\
\text { no. }(\%)\end{array}$ & $\begin{array}{l}\text { mean raw score } \\
\text { (SD) }\end{array}$ & $\begin{array}{l}\text { mean z-score } \\
\text { (SD) }\end{array}$ & $\begin{array}{l}\text { cognitive decrement } \\
\text { no. }(\%)\end{array}$ \\
\hline Episodic memory & $-0.12(0.71)$ & & & $-0.40(0.81)$ & & \\
\hline $\begin{array}{l}\text { RAVLT (immediate recall, } \\
\text { total of trials } 1-5 \text { ) }\end{array}$ & $45.3(8.4)$ & $-0.12(0.71)$ & $29(12.1)$ & $41.0(8.5)$ & $-0.43(0.75)$ & $8(20.0)$ \\
\hline RAVLT (delayed recall) & $9.4(2.8)$ & $-0.11(0.80)$ & $30(12.6)$ & $8.4(3.3)$ & $-0.37(1.01)$ & $9(22.5)$ \\
\hline Working memory / attention & $0.11(1.01)$ & & & $-0.40(0.86)$ & & \\
\hline Digit Span & $15.4(3.3)$ & $0.11(1.01)$ & $31(13.0)$ & $13.5(2.7)$ & $-0.40(0.86)$ & $10(25.0)$ \\
\hline Language & $0.02(0.74)$ & & & $-0.04(0.84)$ & & \\
\hline Category Fluency (animals) & $25.4(5.8)$ & $-0.03(0.79)$ & $25(10.5)$ & $24.3(6.5)$ & $-0.11(0.96)$ & $8(20.0)$ \\
\hline Category Fluency (professions) & $19.1(4.8)$ & $0.07(0.91)$ & $28(11.7)$ & $18.2(4.3)$ & $0.03(0.94)$ & $6(15.0)$ \\
\hline Information-processing speed & $0.02(0.72)$ & & & $-0.49(0.93)$ & & \\
\hline Trail Making Test part $A^{b}$ & $30.5(11.5)$ & $0.19(0.84)$ & $24(10.0)$ & $33.9(12.0)$ & $-0.01(0.85)$ & $6(15.4)$ \\
\hline Stroop Color-Word Test (Card I) & $44.1(8.7)$ & $-0.10(0.99)$ & $46(19.3)$ & $48.0(9.9)$ & $-0.50(1.13)$ & $8(21.1)$ \\
\hline Stroop Color-Word Test (Card II) & $58.9(12.5)$ & $-0.23(1.10)$ & $53(22.3)$ & $66.1(13.9)$ & $-0.84(1.18)$ & $16(42.1)$ \\
\hline Symbol-Digit Substitution Test & $57.6(11.3)$ & $0.05(0.99)$ & $31(13.0)$ & $49.5(10.6)$ & $-0.59(1.10)$ & $11(27.5)$ \\
\hline Executive functions & $0.33(0.68)$ & & & $0.11(0.73)$ & & \\
\hline $\begin{array}{l}\text { Trail Making Test interference } \\
\text { score (Part B/Part A) }\end{array}$ & $2.3(0.7)$ & $-0.13(0.99)$ & $45(18.8)$ & $2.5(0.6)$ & $-0.38(0.92)$ & $9(23.1)$ \\
\hline $\begin{array}{l}\text { Stroop interference score } \\
\text { (Card III/average Card I and II) }\end{array}$ & $1.8(0.3)$ & $0.78(0.71)$ & $4(1.7)$ & $1.9(0.3)$ & $0.61(0.86)$ & $1(2.6)$ \\
\hline
\end{tabular}

Abbreviations: RAVLT Rey auditory verbal learning test

${ }^{a}$ mean standardized age, sex and education-adjusted normative z-scores (SD) are presented for the domains, mean raw scores (SD), as well as mean z-scores (SD), and percentage of subjects with a cognitive decrement ( $z$-score $<1.0$ SD below the age, sex and education-adjusted normative mean) are presented for the separate tests. Higher scores represent better cognitive performance, unless otherwise indicated

${ }^{b}$ higher scores represent worse cognitive performance

study centers by a primary care physician or medical specialty.

In addition to the low prevalence of cognitive impairments in our study, the pathogenesis of impaired cognition in relation to Lyme disease is still unclear, with scarce evidence for underlying central nervous system pathology [31].

A potential limitation of the present study is the absence of a contemporaneous control group of healthy individuals. However, we compared the individuals' performances to a substantially larger normative sample, with specific adjustments for age, education and sex, than would have been ever possible with recruiting our own controls. Additionally, the fact that our study population was more heterogenous than previous studies could be seen as a limitation, and not all patients received previous treatment with antibiotics.

\section{Conclusions}

The present study, taking performance validity into account in a large, well-defined cohort of patients with persistent symptoms attributed to Lyme borreliosis, demonstrates that only a small percentage of patients can be classified as cognitively impaired. Furthermore, self-reported symptoms of cognitive problems are unrelated to performance on neuropsychological tests in patients with Lyme-associated symptoms.

\section{Abbreviations}

ASTM: Amsterdam short term memory test; BSQ: Body sensations questionnaire; CFQ: Cognitive failures questionnaire; CIS: Checklist individual strength; EPQ: Eysenck personality questionnaire; HADS: Hospital anxiety and depression scale; ICQ: IIIness cognition questionnaire; PLEASE: Persistent Lyme Empiric Antibiotic Study Europe; PSWQ: Penn-State Worry Questionnaire; RAVLT: Rey auditory verbal learning test

\section{Acknowledgements}

Not applicable.

\section{Authors' contributions}

Conception and design of the study: $A B, A W M E, H J M H, B J K$, and RPCK. Acquisition and analysis of data: $A B, J A R, H J M H, F J$, and RPCK. Drafting a significant portion of the manuscript: $A B, A W M E, B J K$, and RPCK. All authors read and approved the final manuscript.

\section{Funding}

The study has been funded by the Netherlands Organisation for Health Research and Development (ZonMw). This funding body had no role in the design of the study and collection, analysis, and interpretation of data and in writing the manuscript.

\section{Availability of data and materials}

The datasets used and analysed during the current study are available from the corresponding author on reasonable request. 


\section{Ethics approval and consent to participate}

Ethics approval was obtained from the local Institutional Review Board (CMO region Arnhem - Nijmegen, 2009/187, NL27344.091.09). All participants provided written informed consent.

\section{Consent for publication}

Not applicable.

\section{Competing interests}

The authors declare that they have no competing interests.

\section{Author details}

'Department of Internal Medicine 463 and Radboud Center for Infectious Diseases, Radboud University Medical Center, P.O. Box 9101, 6500, HB, Nijmegen, the Netherlands. ${ }^{2}$ Department of Psychology, University of Amsterdam, Amsterdam, the Netherlands. ${ }^{3}$ Department of Medical Psychology, Radboud University Medical Center, Nijmegen, the Netherlands. ${ }^{4}$ Institute of Psychology, Health, Medical, and Neuropsychology Unit, Leiden University, Leiden, the Netherlands. ${ }^{5}$ Department of Medicine, Sint Maartenskliniek, Nijmegen, the Netherlands. ${ }^{6}$ Donders Institute for Brain, Cognition and Behaviour, Radboud University, Nijmegen, the Netherlands.

Received: 14 May 2019 Accepted: 10 September 2019

Published online: 07 October 2019

\section{References}

1. Kaplan RF, Trevino RP, Johnson GM, Levy L, Dornbush R, Hu LT, Evans J, Weinstein A, Schmid CH, Klempner MS. Cognitive function in posttreatment Lyme disease: do additional antibiotics help? Neurology. 2003; 60(12):1916-22

2. Bechtold KT, Rebman AW, Crowder LA, Johnson-Greene D, Aucott JN. Standardized symptom measurement of individuals with early Lyme disease over time. Arch Clin Neuropsychol. 2017;32(2):129-41

3. Benke T, Gasse T, Hittmair-Delazer M, Schmutzhard E. Lyme encephalopathy: long-term neuropsychological deficits years after acute neuroborreliosis. Acta Neurol Scand. 1995:91(5):353-7.

4. Eikeland R, Ljostad U, Mygland A, Herlofson K, Lohaugen GC. European neuroborreliosis: neuropsychological findings 30 months post-treatment. Eur J Neurol. 2012;19(3):480-7.

5. Gaudino EA, Coyle PK, Krupp LB. Post-Lyme syndrome and chronic fatigue syndrome. Neuropsychiatric similarities and differences. Arch Neurol. 1997; 54(11):1372-6.

6. Keilp JG, Corbera K, Gorlyn M, Oquendo MA, Mann JJ, Fallon BA. Neurocognition in post-treatment Lyme disease and major depressive disorder. Arch Clin Neuropsychol. 2019:34(4):466-80.

7. Keilp JG, Corbera K, Slavov I, Taylor MJ, Sackeim HA, Fallon BA. WAIS-III and WMS-III performance in chronic Lyme disease. J Int Neuropsychol Soc. 2006;12(1):119-29.

8. Krupp LB, Masur D, Schwartz J, Coyle PK, Langenbach LJ, Fernquist SK, Jandorf $L$, Halperin JJ. Cognitive functioning in late Lyme borreliosis. Arch Neurol. 1991;48(11):1125-9.

9. Pollina DA, Sliwinski M, Squires NK, Krupp LB. Cognitive processing speed in Lyme disease. Neuropsychiatry Neuropsychol Behav Neurol. 1999;12(1):72-8.

10. Ravdin LD, Hilton E, Primeau M, Clements C, Barr WB. Memory functioning in Lyme borreliosis. J Clin Psychiatry. 1996;57(7):282-6.

11. Shadick NA, Phillips CB, Logigian EL, Steere AC, Kaplan RF, Berardi VP, Duray PH, Larson MG, Wright EA, Ginsburg KS, et al. The long-term clinical outcomes of Lyme disease. A population-based retrospective cohort study. Ann Intern Med. 1994;121(8):560-7.

12. Touradji P, Aucott JN, Yang T, Rebman AW, Bechtold KT. Cognitive decline in post-treatment Lyme disease syndrome. Arch Clin Neuropsychol. 2019; 34(4):455-65.

13. Shadick NA, Phillips CB, Sangha O, Logigian EL, Kaplan RF, Wright EA, Fossel AH, Fossel K, Berardi V, Lew RA, et al. Musculoskeletal and neurologic outcomes in patients with previously treated Lyme disease. Ann Intern Med. 1999;131(12):919-26

14. Van Dam AP, Kuiper H, Vos K, Widjojokusumo A, de Jongh BM, Spanjaard L, Ramselaar AC, Kramer MD, Dankert J. Different genospecies of Borrelia burgdorferi are associated with distinct clinical manifestations of Lyme borreliosis. Clin Infect Dis. 1993;17(4):708-17.
15. Bar-On Kalfon T, Gal G, Shorer R, Ablin JN. Cognitive functioning in fibromyalgia: the central role of effort. J Psychosom Res. 2016;87:30-6.

16. Berende A, ter Hofstede HJ, Vos FJ, van Middendorp H, Vogelaar ML, Tromp $M$, van den Hoogen FH, Donders AR, Evers AW, Kullberg BJ. Randomized trial of longer-term therapy for symptoms attributed to Lyme disease. N Engl J Med. 2016;374(13):1209-20.

17. Berende A, ter Hofstede HJ, Vos FJ, Vogelaar ML, van Middendorp H, Evers AWM, Kessels RPC, Kullberg BJ. Effect of prolonged antibiotic treatment on cognition in patients with Lyme borreliosis. Neurology. 2019;92(13):1-9.

18. Schagen S, Schmand B, de Sterke S, Lindeboom J. Amsterdam short-term memory test: a new procedure for the detection of feigned memory deficits. J Clin Exp Neuropsychol. 1997;19(1):43-51.

19. Schmand B, Lindeboom J, Schagen S, Heijt R, Koene T, Hamburger HL. Cognitive complaints in patients after whiplash injury: the impact of malingering. J Neurol Neurosurg Psychiatry. 1998;64(3):339-43.

20. Ponds R, van Boxtel M, Jolles J. De 'Cognitive Failure Questionnaire' als maat voor subjectief cognitief functioneren. Tijdschrift Voor Neuropsychologie. 2006;1(2).

21. Bjelland I, Dahl AA, Haug TT, Neckelmann D. The validity of the hospital anxiety and depression scale. An updated literature review. J Psychosom Res. 2002;52(2):69-77.

22. Lorig K, Chastain RL, Ung E, Shoor S, Holman HR. Development and evaluation of a scale to measure perceived self-efficacy in people with arthritis. Arthritis Rheum. 1989;32(1):37-44.

23. Evers AW, Kraaimaat FW, van Lankveld W, Jongen PJ, Jacobs JW, BijJsma JW. Beyond unfavorable thinking: the illness cognition questionnaire for chronic diseases. J Consult Clin Psychol. 2001;69(6):1026-36.

24. Meyer TJ, Miller ML, Metzger RL, Borkovec TD. Development and validation of the Penn State worry questionnaire. Behav Res Ther. 1990;28(6):487-95.

25. Eysenck SBG, Eysenck HJ, Barrett P. A revised version of the psychoticism scale. Pers Individ Dif. 1985;6(1):21-9.

26. Chambless DL, Caputo GC, Bright P, Gallagher R. Assessment of fear of fear in agoraphobics: the body sensations questionnaire and the agoraphobic cognitions questionnaire. J Consult Clin Psychol. 1984;52(6):1090-7.

27. Agelink van Rentergem JA, Murre JM, Huizenga HM. Multivariate normative comparisons using an aggregated database. PLoS One. 2017;12(3):e0173218.

28. Janssen MA, Meulenbroek O, Steens SC, Goraj B, Bosch M, Koopmans PP, Kessels RP. Cognitive functioning, wellbeing and brain correlates in HIV-1 infected patients on long-term combination antiretroviral therapy. AIDS. 2015;29(16):2139-48.

29. Gruters AAA, Ramakers I, Verhey FRJ, Kohler S, Kessels RPC, de Vugt ME. Association between proxy- or self-reported cognitive decline and cognitive performance in memory clinic visitors. J Alzheimers Dis. 2019;70(4):1225-39.

30. Yoon BY, Lee JH, Shin SY. Discrepancy between subjective and objective measures of cognitive impairment in patients with rheumatoid arthritis. Rheumatol Int. 2017;37(10):1635-41.

31. Halperin JJ. Lyme disease: neurology, neurobiology, and behavior. Clin Infect Dis. 2014:58(9):1267-72.

\section{Publisher's Note}

Springer Nature remains neutral with regard to jurisdictional claims in published maps and institutional affiliations.

Ready to submit your research? Choose BMC and benefit from:

- fast, convenient online submission

- thorough peer review by experienced researchers in your field

- rapid publication on acceptance

- support for research data, including large and complex data types

- gold Open Access which fosters wider collaboration and increased citations

- maximum visibility for your research: over $100 \mathrm{M}$ website views per year

At $\mathrm{BMC}$, research is always in progress.

Learn more biomedcentral.com/submissions 